\title{
Desacuerdos fácticos, responsividad y calidad de la democracia. La experiencia del desendeudamiento argentino (2003-2014)
}

Factual disagreements, responsiveness and the quality of democracy. The experience of Argentinian debt-reduction (2003-2014)

\author{
DANTE AVARO \\ Consejo Nacional de Investigaciones Científicas y Técnicas (CONICET, Argentina)
}

\section{Cómo citar/Citation}

Avaro, D. (2017). Desacuerdos fácticos, responsividad y calidad de la democracia. La experiencia del desendeudamiento argentino (2003-2014). Revista Española de Ciencia Política, 44, 67-96. Doi: https://doi.org/10.21308/recp.44.03

\section{Resumen}

Este trabajo incorpora los desacuerdos fácticos como un articulador conceptual entre la responsabilidad y la responsividad. Dentro de este marco conceptual se analiza la política de «desendeudamiento» llevada a cabo por el Gobierno argentino entre 2003 y 2014, lo que permite argumentar que si bien hay consenso en afirmar que la responsividad es un atributo positivo para la democracia, su existencia no se traduce siempre en un hecho valioso para la calidad de la democracia; para que así suceda, la responsividad tiene que ir acompañada de la legitimación de los desacuerdos fácticos, hecho que no ha sucedido en el período analizado. El trabajo describe la existencia de un deficiente desempeño institucional de la Oficina Nacional de Crédito Público para procesar y legitimar los desacuerdos fácticos, impidiendo que la responsividad del Gobierno hacia los ciudadanos se tradujera en una mejora de la calidad de la democracia argentina.

Palabras clave: calidad de la democracia, responsividad, desacuerdos doxásticos, responsabilidad, desacuerdos fácticos.

\begin{abstract}
This work incorporates factual disagreements as a conceptual hinge between responsibility and responsiveness. Within this conceptual framework, I analyze the policy of debt relief carried out by the Argentine Government between 2003 and 2014. Based on this analysis, it is argued that, although there is a consensus that responsiveness is a positive attribute for democracy, its existence does not always become a valuable fact for the quality of democracy. In order for this
\end{abstract}


to take place, responsiveness must be accompanied by the legitimacy of factual disagreements, which has not occurred in the analyzed period. This paper describes the existence of a deficient institutional performance within the National Public Credit Office to process and legitimize factual disagreements, which has prevented the government's responsiveness towards citizens to lead to an improvement in the quality of Argentine democracy.

Keywords: quality of democracy, responsiveness, doxastic disagreements, responsibility, factual disagreements.

\section{INTRODUCCIÓN}

En este trabajo incorporo los desacuerdos fácticos al análisis de la responsividad . Propongo un esquema analítico-conceptual que permita comprender la interacción de aquella con la responsabilidad, entendidas ambas como atributos valiosos para la calidad de la democracia. La responsabilidad se suele invocar en los casos en que hacer lo que los ciudadanos desean y prefieren pudiera resultar, dadas la conexiones teórica asumidas respecto de la teoría democrática, un empeoramiento antes que un mejoramiento de la calidad de la democracia. Así, no siempre la falta o ausencia de responsividad indica una oportunidad perdida para mejorar la calidad de la democracia. Pudiera suceder, tomando en cuenta los efectos negativos que la respuesta política pudiera producir en los contenidos y/o en los procedimientos, que la prioridad de la responsabilidad resulte conveniente para evitar un empeoramiento de la calidad democrática. Sin embargo, ¿cómo interviene la responsabilidad en los casos en que hacer lo que los ciudadanos desean y prefieren parece, intuitivamente y desde la teoría, una situación de mejora en la calidad de la democracia?

Para avanzar en mi propósito analizo la política «desendeudamiento» $»^{2}$ llevada a cabo por el Gobierno argentino desde 2003 hasta 2014. En esta política confluyen los elementos necesarios para abordar la cuestión planteada. Primero, resulta posible establecer que el «desendeudamiento» consiste en una respuesta del Gobierno a las preferencias y deseos de los públicos ciudadanos. Segundo, que la política de «desendeudamiento» se convalidó en dos elecciones presidenciales. Tercero, hacer lo que los ciudadanos desean y prefieren en materia de «desendeudamiento» va de la mano con los conocimientos teóricos que sostienen que a menor deuda soberana, mayor capacidad democrática para

1. En la literatura especializada se han ofrecido diferentes traducciones para el concepto responsiveness. Entre las más utilizadas se encuentra «reciprocidad» y «respuesta política». En este trabajo, continuando con la propuesta de J. J. Linz (2009: cap. 11) y sus editores, utilizo «responsividad». En Avaro (2015: 57-60) el lector encontrará una descripción más detallada sobre las diferentes traducciones disponibles vis à vis de la red conceptual responsiveness.

2. «Desendeudar» no aparece en el Diccionario de la Real Academia. Su utilización en este texto se justifica, ya que fue la nominación escogida por el Gobierno argentino para denotar en público la acción de disminuir la deuda. 
tomar decisiones públicas, lo que promueve una mejora en la calidad de la democracia. Así, el «desendeudamiento» argentino parece ser el típico caso en donde hacer lo que los ciudadanos desean y prefieren no solo resulta un atributo valioso para la calidad de la democracia, sino que además el contenido de la acción política, en función de los conocimientos teóricos disponibles, permite vincular positivamente la disminución de la deuda soberana con una mayor autonomía de las decisiones públicas, asunto también valorado positivamente por la calidad de la democracia. Además, encaja en la pregunta: ¿cómo opera la responsabilidad en los casos en que la responsividad no parece conflictiva o anómala para la teoría democrática?

Entre los años 2003 y 2014, los desacuerdos doxásticos sobre qué hacer con la deuda soberana se fueron procesando y legitimando a través de dos elecciones presidenciales (2007 y 2011), lo que dio por resultado la implementación de la política denominada «desendeudamiento». Las preferencias y deseos ciudadanos (la legitimación de qué hacer con la deuda) por un lado, y los actos autoritativos gubernamentales (política de desendeudamiento) por el otro, conformaron un sendero de responsividad que le permitió al Frente para la Victoria (FPV) -la alianza política que gobernó Argentina entre 2003 y 2015- mantenerse en el poder durante tres períodos presidenciales. Sin embargo, a partir del control de divisas implementado en 2012 (AFIP, 2012; Donovan, 2014; Ley 26 739) y, fundamentalmente, con el rechazo a la apelación interpuesta en la Suprema Corte de Nueva York, la sentencia firme del juez Griesa de junio de 2014 a favor de los holdouts y la respuesta política que realizó el Gobierno argentino (Ley 26 984), diferentes públicos ciudadanos comenzaron a cuestionar en dos planos aquel sendero de responsividad: en el plano doxástico (como era de esperar en estos casos) pero, principalmente, en el plano fáctico. Lo interesante de las reflexiones llevadas a cabo por diferentes públicos ciudadanos no radica en que cuestionaban retrospectivamente la política de "desendeudamiento", sino que reclamaban criterios para medir aquello que antes creían y ahora dudaban: los resultados. ¿Cuánto debe Argentina? ¿Si pagamos, cómo es que debemos? ¿Estamos o no en default? ¿A quiénes debemos? ¿Desde cuándo? ¿A cuánto asciende el principal, a cuánto los intereses? Fueron, entre otras, las preguntas más recurrentes que los diferentes públicos que conforman la opinión pública argentina realizaron entre los años 2014 y 2015, cuyas respuestas fueron no solo parciales, sino variadas y también disímiles.

Entiendo que este caso no corresponde a una escalada de desacuerdos doxásticos producto del éxito o fracaso de una política, sino más bien a si los públicos ciudadanos contaban o no con elementos para enjuiciar los resultados de una política presentada como «exitosa» por parte del Gobierno (MECON, 2015). Esto muestra que los públicos ciudadanos no visualizaban los espacios institucionales pertinentes ni los criterios utilizados para procesar los desacuerdos fácticos (Kappel 2014); y al no visibilizarlos terminaron dudando de la consistencia sobre el sendero previo de responsividad. Para cada una de aquellas preguntas formuladas por los públicos ciudadanos había: a) principios epistémicos incompatibles; b) confianza en diferentes autoridades epistémicas, y c) interpretaciones alternativas sobre las evidencias. Lo central aquí, tomando en cuenta los propósitos de este trabajo, no consiste en que tanto ciudadanos como 
expertos mantengan desacuerdos sobre los hechos, sino en preguntarse si para obtener una mayor comprensión de la responsividad se requiere incorporar, y cómo, la falta de legitimidad para procesar los desacuerdos fácticos. Porque aun suponiendo que resulte posible, mediante un indicador específico, mostrar que, efectivamente, se verificó el "desendeudamiento", y que ese dato se relaciona, teóricamente, con una mejoría en la calidad de la democracia, tendríamos que aceptar que las demandas de los diferentes públicos ciudadanos referidas a la ausencia de espacios y criterios para procesar los desacuerdos fácticos, no afectan la calidad de la democracia. Lo anterior resulta algo contraintuitivo en la práctica democrática y, además, contradictorio con el andamiaje teórico que sirve de sustento a la perspectiva de la calidad de la democracia.

Sin perder de vista que la responsividad es un atributo de la democracia, cuya existencia resulta positiva para la calidad de la misma, también resulta necesario precisar que entre declamar que se hace lo que los ciudadanos desean y prefieren y hacerlo, media una prueba, una forma de observación intersubjetiva que sirva para convalidar (o no) el sendero de responsividad. Para el caso del «desendeudamiento» argentino la «observación» debería ser capaz de rastrear información sobre el procesamiento de los desacuerdos fácticos, dado que es este asunto el que produce desconcierto entre los públicos ciudadanos. El aporte de este trabajo consiste en incorporar al nivel de la "observación», información sobre el funcionamiento del espacio institucional encargado de procesar los desacuerdos fácticos. El objetivo es mostrar cómo el procesamiento de los desacuerdos fácticos permite comprender más adecuadamente la interacción de la responsividad con la responsabilidad, no solo en los casos de prioridad de la segunda sobre la primera, sino también en los que esa precedencia no es requerida con antelación por intuiciones teóricas.

En el segundo apartado, argumento que la responsabilidad no solo resulta relevante en las situaciones en que el Gobierno no hace lo que los ciudadanos desean y prefieren, sino que también resulta necesaria para los casos en que sí lo hace. En el tercer apartado sitúo los desacuerdos fácticos, sus espacios institucionales, sus criterios para procesar los desacuerdos, como un aspecto relevante de la responsabilidad. De forma tal que la legitimación de los desacuerdos fácticos constituye una dimensión relevante para analizar cuando un Gobierno hace lo que los ciudadanos desean y prefieren.

En el cuarto apartado introduzco brevemente la importancia que tiene la deuda soberana en la arena democrática argentina contemporánea. Continuando en la línea de otros estudios, relaciono teóricamente la disminución de la deuda como un elemento positivo para la mayor soberanía democrática. Utilizando datos oficiales analizo, en primer lugar, la relación entre deuda y el producto bruto interno (PBI). Muestro sus limitaciones para el caso argentino. En segundo lugar, propongo cinco variables con el propósito de observar el comportamiento del «desendeudamiento». Individualmente y en conjunto estas variables responden a la intuición teórica: a menor endeudamiento mayor autonomía democrática. Esta intuición teórica recorre algunas propuestas de calidad de la democracia, que trato de justificar para el caso argentino.

En el quinto apartado incorporo los desacuerdos fácticos al análisis realizado en el apartado anterior. En primer lugar, identifico el espacio institucional que la 
democracia argentina posee para procesar los desacuerdos fácticos en torno a la cuestión de la deuda: la Oficina Nacional de Crédito Público (ONCP). Mediante el análisis de los Informes anuales de la Auditoría General de la Nación (AGN), un total de diceséis informes, se procedió a contrastar los objetivos propuestos por el legislador en el momento de crear ese espacio institucional con las debilidades que a lo largo de dieciocho años detectó la AGN. Identifico tres criterios al interior de la ONCP. Estos permiten observar en qué dirección deberían ir el trabajo de los expertos y la legitimación de los desacuerdos fácticos. A su vez, con esos mismos criterios se recabó información de los documentos oficiales de la AGN, lo que permitió establecer un listado de debilidades por parte de la $\mathrm{ONCP}$ para legitimar los desacuerdos fácticos.

\section{RESPONSIVIDAD Y RESPONSABILIDAD}

La calidad de la democracia constituye un objeto de estudio que tiene el propósito de evaluar la calidad de ciertos atributos de las democracias ${ }^{3}$. Los estudios sobre la calidad de la democracia se han sustentado, entre otras fuentes, en el trabajo pionero de Morlino y su enfoque tridimensional: procedimientos, contenidos y resultados (Morlino, 2004a; 2004b). Simplificando y generalizando, los estudios abocados a la calidad de la democracia utilizan $m$ dimensiones, subdividas en $n$ subdimensiones, conformadas por $k$ variables. En este sentido, la agenda de la calidad de la democracia ha venido discutiendo la pertinencia de las dimensiones, especialmente por la naturaleza y alcance de la dimensión «resultados» (Munck, 2011). Entre otras, porque al interior de esta dimensión existe una delgada línea divisoria entre calidad de la democracia y calidad del gobierno que no siempre queda bien delimitada (Cejudo et al., 2009). En este contexto, y más allá del peso ponderado que cada investigación le adjudica a las variables, subdimensiones y dimensiones, los estudios de la calidad de la democracia no parecen orientarse al análisis y cuantificación de los efectos marginales de las «políticas» sobre la calidad de la democracia ${ }^{4}$. En cambio, sí se ocupan, en líneas generales, por indagar, mediante la construcción de índices, cómo evoluciona la calidad entre las

3. Entiendo por «agenda de la calidad de la democracia» las reflexiones, argumentos, discusiones y acuerdos que expertos y especialistas brindan para delimitar un campo de estudio y/o programa de investigación. Entiendo por «estudios de la calidad de la democracia» el conjunto de investigaciones y sus resultados sobre dicha temática. Y me refiero a la "calidad de la democracia» como el objeto empírico construido desde la agenda de la calidad de la democracia y puesto a prueba en los estudios.

4. Es por esta razón, quizá, que en los estudios de la calidad de la democracia hay una marcada ausencia de recomendaciones de políticas para promover la calidad democrática (Morlino et al., 2014: 75 y ss.). En el mismo sentido, la agenda de la calidad de la democracia no ha concentrado sus esfuerzos en desarrollar una metodología que permita cribar las políticas que mejoran los rendimientos de la democracia de aquellas que mejoran la calidad de las instituciones democráticas (Avaro, 2016a). 
democracias y, cuando resulta posible, a lo largo del tiempo (Munck, 2006: 166; Munck y Verkuilen, 2002: passim).

La responsividad, cuya historia en la ciencia política anglosajona precede a su utilización en la calidad de la democracia, ocupa un rol destacado en la dimensión «resultados» (Erikson, 2013; Vidal de la Rosa, 2015; Avaro, 2015). Aunque muchos se han ocupado de este tema, fue el tratamiento propuesto por Dahl, tanto en Poliarquía como en La democracia y sus críticos, el que ejerce mayor influencia en los estudios de la calidad de la democracia. Dahl (1972: 1) afirmó que la democracia tiende a la responsividad, pero esta no constituye o interviene en la definición de aquella. La democracia hace que los Gobiernos tomen decisiones e implementen políticas que los ciudadanos desean y prefieren; sin embargo que los Gobiernos hagan lo que los ciudadanos desean y prefieren no constituye lo que la democracia es. Así, el que se pueda corroborar la existencia de responsividad es tomado en cuenta como un indicio, entre otros, de la mejora de la calidad de la democracia. Tanto Dahl, y especialmente Pitkin (1967), advierten que en el análisis de la responsividad resulta necesario excluir los casos atribuidos a la casualidad (suerte y azar) y centrarse en la causalidad. Aunque esta sea difícil de reconstruir para explicar aquella, no resulta una tarea fútil intentar explorar la cadena de posibles imputaciones existentes entre, por un lado, los deseos y preferencias de los ciudadanos y, por otro, las decisiones públicas. Las cadenas causales son relevantes ya que filtran los componentes azarosos y la buena fortuna que pueden influir en la responsividad, dejando a las respuestas gubernamentales justo en el lugar apropiado para su análisis: a nivel de las decisiones autoritativas basadas en evidencias, diagnósticos y utilización de conocimiento-expertise. A los ciudadanos probablemente les interese que no solo se satisfagan sus preferencias (responsividad), sino que ello se haga de la mejor manera posible, es decir, es altamente probable que les interese que el gobierno tome buenas decisiones, que implemente buenas políticas.

La cuestión de la responsividad, según Powell (2005), requiere reconstruir, dentro del proceso político, una cadena de acciones e intenciones que vinculen los deseos y preferencias de los ciudadanos por $x$ con las decisiones públicas direccionadas o ubicadas en torno a $x$. La complejidad no solo recae en cómo operacionalizar el contenido de la frase «lo que los ciudadanos deseen y prefieran», sino en que $x$ puede llegar a ser resultados, políticas y/o una conjunción de ambas. Hasta donde sé, no existe una propuesta acabada sobre el alcance o cobertura de lo que está sujeto a responsividad dentro de la agenda de la calidad de la democracia. Creo que ello es pertinente en razón de que: a) no le compete a los investigadores juzgar los deseos y preferencias de los ciudadanos, y también porque b) los deseos y preferencias de los ciudadanos y las decisiones públicas conforman un espacio dinámico -dynamic responsiveness- (Stimson et. al. 1995). Por ello, los investigadores, condicionados en muchas ocasiones por la disponibilidad de datos y siguiendo sus propias jerarquizaciones analíticas, han desarrollado múltiples ejercicios que se pueden agrupar en tres: a) rastreo de senderos de no-responsividad (Schumaker, 1975); b) identificación de "políticas» frente a problemas priorizados en la opinión pública (Wlezien, 2005), y c) utilización de indicadores que dan cuenta de la situación socioeconómica de la sociedad. Ante la compleja perspectiva de 
reconstruir la cadena causal, admitida por el propio Powell (2005), los estudios que utilizan la responsividad para abordar la dimensión resultados han optado por estrategias más débiles pero valiosas para el desarrollo de los estudios sobre la calidad de la democracia. Según estas, resulta posible indagar sobre la responsividad cuando: a) ciertos resultados o rendimientos de variables, que se presuponen relevantes para la calidad de la democracia, pueden imputarse a decisiones públicas y a su vez se conectan con alguna política; b) identificados los deseos y preferencias de los ciudadanos y detectada una política, observar si resulta posible conectar teóricamente los resultados con la calidad de la democracia, o bien c) dada una política y si resulta posible identificar su convalidación electoral (sendero de legitimación de desacuerdos doxásticos), establecer la conexión entre la dirección de los resultados y la calidad de la democracia.

Aunque la «dimensión resultados» está hecha, por decirlo de algún modo, de políticas, la responsividad no busca cribar y jerarquizar el efecto de las políticas sobre la calidad de la democracia, sino que pondera la calidad de la democracia en función de la respuesta política de los Gobiernos frente a los deseos y preferencias de los ciudadanos.

La responsividad, como paraguas conceptual, intenta capturar si los Gobiernos hacen lo que los ciudadanos desean y prefieren valorando esta conexión como atributo positivo de la democracia y no como efecto marginal de las políticas, tal cual pudieran hacerlo específicamente los estudios sobre la calidad del gobierno. Así, las iniciativas gubernamentales no deseadas ni preferidas por la ciudadanía pueden mejorar la calidad de la democracia, pero quedan fuera del alcance del concepto de responsividad. Sin embargo, el reverso de lo anterior es uno sus mayores desafíos. Dado que los deseos y preferencias de los ciudadanos son soberanos, es en esa fulminante soberanía que pueden demandar politicas que, en caso de ser atendidas (responsividad), terminen afectando negativamente la calidad de la democracia. Para enfrentar esta situación el trabajo seminal de Pennock (1952) trazó una ruta analítica que resulta difícil de evitar: la responsividad se complementa aguas abajo con la representación y aguas arriba con la responsabilidad.

Si bien la calidad de la democracia asume que la democracia tiende a la responsivi$\mathrm{dad}$, puede suceder en algunos casos que la ausencia de esta no solo se deba a la negativa del Gobierno de atender a las demandas ciudadanas, sino a la prioridad que tiene la responsabilidad en la respuesta gubernamental, bajo el entendimiento de que la calidad de la democracia no solo se basa en los resultados, sino también en los procedimientos y los contenidos de la democracia. Así, no en todos los casos de no-responsividad estamos en presencia de pérdida de calidad de la democracia, ya que si interviene la prioridad de la responsabilidad frente a la respuesta gubernamental, esto podría poner de manifiesto la intención del Gobierno por evitar un empeoramiento de la calidad. Así, si la responsabilidad cumple un rol fundamental en los casos de no-responsividad, también resulta necesaria para aquellos en que sí la hay, de lo contrario sería un atajo ad hoc de la teoría.

En el próximo epígrafe sostendré que la institucionalización y legitimación de los desacuerdos fácticos son un buen candidato para observar el papel atribuido a la responsabilidad en la comprensión de la responsividad. 


\section{RESPONSIVIDAD Y DESACUERDOS FÁCTICOS}

El proceso democrático no puede renunciar a la responsividad, pero tampoco el científico puede ignorar que las mejores decisiones, en el sentido de las «mejores políticas», están situadas (y sitiadas) en el terreno de los desacuerdos doxásticos 5 . En otras palabras, desacuerdos de intereses, creencias y juicios normativos sobre diferentes asuntos hacen que las políticas se sometan a la representación, esto es, a la esfera de legitimación de los desacuerdos doxásticos que toda democracia moderna cuida, protege y reverencia. De modo que si la democracia, para serlo, no puede renunciar a que el Gobierno gobierne por medio de políticas (Aguilar Villanueva, 2007) orientadas a la responsividad, a la vez que existan espacios para legitimar los desacuerdos doxásticos, tampoco la democracia puede pasar por alto que el Gobierno para gobernar por medio de políticas requiere ajustarse a las evidencias, esto es, no puede renunciar a la responsabilidad (Pennock 1952). Esta constituye un elemento irreductible del Gobierno por medio de políticas, ya que funda la posibilidad de una argumentación pública, permite la acción evaluativa por parte de los ciudadanos, habilita la rendición de cuentas y favorece la reformulación de los contenidos en los debates doxásticos que entablan los ciudadanos.

Las divergencias de intereses, creencias y juicios normativos que pueden tener los ciudadanos al vincularse con la oferta de transformación pública que ofrecen los políticos, construye un espacio entre representación y responsividad que etiqueto como desacuerdo doxástico, y que la regla de contar cabezas (Rosanvallon, 2007) legitima periódicamente, lo que permite que el demócrata pueda vivir bajo leyes y políticas que no ha votado, pero que considera legítimas y que, además, obedece (Przeworski, 1997; 2010). Esa fuerza política incuestionable que tienen las democracias caracterizada por la relación entre representación y políticas constituye el centro de la responsividad (Mair, 2009: 13 y ss.) y legitima la existencia de los desacuerdos doxásticos. Sin embargo, la modificación no azarosa sino proteica de los asuntos públicos por medio de políticas, es decir, la responsividad visible a través de actos autoritativos (políticas), se enfrenta inmediatamente con desacuerdos ciudadanos en torno a cómo se valoran las evidencias del asunto público en cuestión, en desacuerdos de expertos sobre cómo se soluciona, con qué herramientas y recursos y, también, en divergencias de paradigmas epistémicos para argumentar sobre las evidencias y las soluciones a los problemas. Si bien los desacuerdos fácticos son ineliminables, la democracia no renuncia a legitimarlos. Esta es una tarea indelegable de una democracia de calidad ya que aquí se instaura el espacio que media o procesa la responsividad con la responsabilidad de los actos autoritativos. Estos desacuerdos no son sobre intereses, creencias o cuestiones normativas, sino que son desacuerdos sobre la verdad o falsedad de proposiciones referidas a

5. Peter Mair (2015: 22 y ss.) introduce el concepto de indiferencia ciudadana para explorar la tensión entre responsividad y responsabilidad al interior de los partidos políticos, encargados, entre otras cosas, de canalizar los desacuerdos doxásticos (Bardi et al., 2014). 
ciertos asuntos públicos. Solamente legitimando los desacuerdos fácticos un Gobierno puede volverse responsable por los actos autoritativos que emprende. Le permite argumentar por las políticas que implementa, rendir cuenta del ejercicio del poder, al tiempo que el público ciudadano accede a herramientas para evaluar y juzgar las políticas.

La utilidad pública de procesar los desacuerdos fácticos no radica en evaluar contrafácticamente las decisiones que un Gobierno toma, sino en que las políticas que materializan las decisiones sean las mejores dentro de un conjunto siempre falible de evidencias y conocimientos. Legitimar los desacuerdos fácticos no resulta en procesar, dirimir, consensuar, achicar las brechas entre las posturas epistémicas enfrentadas, aunque ello pueda ocurrir porque estamos localizados en un plano de interacciones humanas; legitimarlos, por el contrario, implica gobernar por medio de políticas, descontando que esos desacuerdos son ineliminables, ya que hay ciudadanos y expertos que no evalúan los asuntos de la misma manera. Legitimar los desacuerdos fácticos desde la perspectiva democrática -i.e. donde el Gobierno gobierna por medio de políticas- implica enfrentar el desafío de producir democráticamente (es decir, en el plano de los desacuerdos doxásticos) espacios institucionales con criterios visibles e identificables para el público ciudadano. De modo que esta sería la trama institucional en donde el Gobierno utiliza conocimiento y la expertise para gobernar.

\section{EL «DESENDEUDAMIENTO»ARGENTINO 2003-2014}

El endeudamiento en los estudios pioneros sobre la calidad de la democracia que incorporan la dimensión «resultados» (Morlino 2004a y 2004b), no se encuentra directamente explicitado, aunque subyace a los outputs que la dimensión pretende medir. Lo mismo sucede en los estudios de la calidad del gobierno (Kraay et al., 2010). Sin embargo, trabajos recientes (Levine y Molina, 2011a, 2011b) incorporan la «deuda» en la dimensión «soberanía». El argumento teórico para incorporar la deuda en la agenda de la calidad democrática es el siguiente: una democracia al estar endeudada pierde autonomía en su proceso decisorio. El tamaño del endeudamiento se relaciona directamente con las potenciales injerencias que los acreedores ejerzan sobre la soberanía democrática, lo que genera una cuña de legitimidad entre lo que probablemente prefieran-decidan los ciudadanos y lo que es útil para los acreedores ${ }^{6}$. Por tanto,

6. Actualmente, un $47 \%$ de los ciudadanos argentinos encuestados por el Latinobarómetro está en desacuerdo con incrementar los impuestos y/o la deuda para financiar obras de infraestructura que mejoren la competitividad argentina. La encuesta fue realizada en 2015, y se basó en 1200 entrevistas. La pregunta decía: «¿Cuánto está usted dispuesto a que se aumenten los impuestos y/o el país se endeude para financiar obras de infraestructura que favorezcan la integración de su país con el mundo (puentes, autopistas, aeropuertos, puertos). En una escala de 1 a 10». El porcentual citado agrupa las respuestas brindadas en 1, 2 y 3 . Datos disponibles en: http:// www.latinobarometro.org/latOnline.jsp (consulta: 15-2-2017). 
a partir de un umbral, difícil de establecer, los «terceros observantes» (Rosanvallon, 2007) dejan de cumplir para los ciudadanos el rol de meros observadores para convertirse en policymakers, quienes, desde la perspectiva de la soberanía democrática, carecen de legitimidad para pergeñar o influenciar en los actos autoritativos ${ }^{7}$.

En la arena política argentina, la «deuda soberana» produjo y produce múltiples desacuerdos doxásticos en el interior de los diferentes públicos que conforman la opinión pública argentina. Por un lado, se aglutinan los que creen, con diferentes y múltiples énfasis, que honrar las deudas es una forma de generar confiabilidad en el mercado internacional. Pero también están aquellos que sostienen, invariablemente desde el retorno a la democracia en 1983, que la "deuda» argentina es «ilegítima» y que no debe pagarse. La «ilegitimidad», en esta forma de ver el asunto, proviene de dos hechos: una parte de la deuda fue contraída por Gobiernos no democráticos (fundamentalmente la dictadura militar de 1976-1983) o por Gobiernos democráticos, pero corruptos e irresponsables (el proceso de privatizaciones realizado bajo la administración del presidente Menem). Esta postura no solo no es market friendly, sino que es políticamente incómoda, involucra a la famosa "patria contratista» de la dictadura (y sus posteriores conexiones democráticas) y a los «empresarios» insiders que, con información privilegiada, operaron en los procesos de reestructuración de deuda. Así, un primer desacuerdo doxástico consiste en pagar o declarar unilateralmente el no pago hasta conocer qué deuda es o no legítima.

En Argentina, desde el retorno a la democracia en 1983, ningún Gobierno, con excepción del período bajo análisis, tuvo un discurso y acciones políticas concretas sobre el «desendeudamiento». Tanto el Gobierno de Alfonsín (1983-1989), como de Menen (1989-1999) y el de De La Rúa (1999-2001), que desembocó en la decisión del entonces presidente Rodríguez Saá de declarar el default en 2001, terminaron sus administraciones con un nivel de deuda soberana mayor al que habían comenzado su gestión. El segundo gran desacuerdo está ubicado en enfrentar las demandas sociales con mayor endeudamiento.

La situación argentina ejemplifica muy bien la idea de que la deuda constituye un asunto público típicamente intergeneracional. En democracia, los ciudadanos que están obligados a cancelar las deudas saben que los que se endeudaron no eran ciudadanos muy diferentes a ellos. Por medio de sus representantes, decidieron, según las razones y argumentos esgrimidos en su presente, asignar una carga futura que a posteriori se hizo

7. Durante el año 2001, año de la cesación unilateral de pagos, los ciudadanos argentinos tenían una percepción muy negativa de los «terceros observantes». Según datos del Latinobarómetro, la evaluación de los ciudadanos argentinos con respecto al Fondo Monetario Internacional (FMI) tiene el siguiente comportamiento: en 2001 un $49 \%$ de los ciudadanos encuestados tenía una evaluación bastante negativa sobre el FMI; en 2009 un 32\%; en 2010 un 33\%, y en 2011 cayó al $21 \%$. Datos provenientes de la pregunta: «De la lista de instituciones que están en la tarjeta, póngale nota de 1 a 10 a las siguientes instituciones internacionales, siendo 0 muy malo y 10 muy bueno». El porcentual citado agrupa las respuestas brindadas en 1, 2 y 3. Datos disponibles en: http://www.latinobarometro.org/latOnline.jsp (consulta: 15-2-2017). 
presente. El deudor difícilmente elude la tentación de analizar la deuda como un asunto de justicia distributiva intertemporal, i.e. cuestionando las opciones políticas pasadas. Sin embargo, la democracia también permite que las generaciones que tienen que pagar, contraten (nueva) deuda que otras, por venir, deberán asumir, y así el ciclo continúa. Y esto es así, entre otras cosas, porque endeudarse resulta una herramienta atractiva desde la perspectiva de la política pública, y es altamente probable que ninguna democracia quiera (o pueda) prescindir de ella. Es por esa razón que resulta pertinente incorporar la deuda en los estudios y mediciones sobre la calidad democrática en su dimensión «resultados». De esta manera, si bien parece pertinente afirmar que existe un punto de equilibrio hipotético (el umbral citado antes) entre deuda y autonomía o soberanía política, también resulta necesario recordar que la deuda es una herramienta de política pública útil y necesaria para la responsividad. Porque al fin y al cabo, muchas demandas ciudadanas solo se pueden atender a costa de incrementar la deuda. Así, no se puede abstraer la relación entre deuda y calidad democrática por fuera de los desacuerdos doxásticos en los que está inmersa la democracia.

Sin embargo, en otras ocasiones primero hay que pagar para que el ciclo vuelva a reiniciarse, y en otras, todavía, pagar para no endeudarse, como parece ser la intención política del «desendeudamiento» iniciada durante el primer mandato presidencial del FPV. En diciembre de 2005, cuando el presidente Kirchner se encontraba a la mitad de su mandato, impulsó una iniciativa gubernamental que hilvanó un proceso de legitimación de los desacuerdos doxásticos que perduró hasta el fin del mandato presidencial de Cristina Fernández Kirchner (CFK): «desendeudarse». No ignoro aquí que el «desendeudamiento» es motivo de disputas doxásticas entre los ciudadanos; por ejemplo, mientras algunos ciudadanos postulan como un acontecimiento positivo el pago por adelantado al FMI con el argumento de que este organismo no tenga más la posibilidad ni la excusa para convertirse en policymaker, otros visualizan en este hecho la imposibilidad de contar con un "tercero observante» para que tanto el Gobierno como la oposición puedan reflexionar sobre la marcha de asuntos económicos e institucionales. Sin embargo, lo que quiero enfatizar es que la política de «desendeudamiento» que llevó a cabo el FPV ha sido respaldada ampliamente en dos procesos electorales presidenciales (2007 y 2011), y es en ese sentido que el desacuerdo tiene legitimidad, i.e. es aceptado por los demócratas que reconocen que en democracia podemos vivir bajo leyes y políticas que no son de nuestra preferencia (Przeworski 1997, 2010). Así, la política de «desendeudamiento» implementada por el FPV a lo largo de tres administraciones presidenciales construyó un sendero de responsividad que legitimó los desacuerdos doxásticos sobre el asunto de la deuda en la democracia argentina.

Ahora bien, ¿cómo medir los resultados de la política? ¿Qué hay que observar para ofrecer una prueba intersubjetiva que verifique el «desendeudamiento»? La proporción deuda/PBI, utilizada en muchos debates (Rogoff y Reinhart, 2011), es un indicador bastante aceptado para medir los resultados de una política de reducción de deuda.

Según datos del Ministerio de Economía y Finanzas Públicas de la República Argentina, hacia finales de 2003, la proporción requerida del PBI para cubrir la deuda 
que la democracia había contraído y/o aceptado hasta ese momento era de 1'39 veces, mientras que para el año 2012 era de apenas 0’415 veces (MECON, 2015). Al tomar en cuenta la deuda en moneda extranjera como porcentaje de las exportaciones, se observa que, hasta el año 2008, la política de desendeudamiento operó acompañada por el incremento en las exportaciones, dando lugar al punto más bajo para los años 2000-2013. Cuando analizamos la proporción deuda en moneda extranjera o reservas, el punto de menor impacto para las reservas se logra para los años 2007 y 2008 (Avaro, 2014: gráficos 1 y 2).

En octubre de 2007, al ganar CFK las elecciones presidenciales que la llevaron a ejercer su primer mandato, se vuelve a legitimar la política de «desendeudamiento» iniciada por el expresidente Kirchner entre 2005 y 2006, lo que le permite al FPV continuar con dicha política. Durante el período 2008-2013, la tasa de crecimiento del PBI a precios constantes ha sido fluctuante, aunque la deuda externa total como porcentaje del PBI tiene un comportamiento descendente. Al analizar el saldo de deuda pública del Gobierno Central como porcentaje del PBI, se observa que es en el año 2011 donde tiene su menor valor (Avaro, 2014: gráficos 3 y 4). Así, en términos generales, el partido en el Gobierno pudo, durante el año electoral 2011, mostrar que tanto la deuda externa total como la deuda pública mostraban que la política de «desendeudamiento» era real y estaba operando.

Resumiendo, desde diciembre de 2005, cuando el presidente Néstor Kirchner anuncia la cancelación de la deuda con el FMI, la política de «desendeudamiento» establece un sendero de responsividad que fue puesto a prueba en dos ocasiones, y en ambas se logró legitimar el desacuerdo doxástico sobre qué hacer con la deuda en la democracia argentina.

Ahora bien, aunque los indicadores deuda/PBI o reservas/deuda suelen ser usados para indicar la «autonomía» (dependencia) «económica» (Levine-Molina, 2011a, 2011b) de una democracia, en el caso bajo estudio pueden ser engañosos para el primer tramo del análisis, y ello por dos razones: a) luego de la fabulosa recesión comenzada en 1998, aunado a la devaluación postconvertibilidad, el efecto "rebote» sobre el PBI constituye un resultado que debe ser aislado en el estudio de los efectos de la política de «desendeudamiento»; b) por el lado de las reservas, en el primer tramo del gobierno del FPV, la permanencia en default y el extraordinario precio de las commodities no deberían ser tomados por sí solos para reflejar los resultados de la política de «desendeudamiento». A lo que se agrega que, en general, estos indicadores son económicamente ambiguos por dos razones cruciales: en primer lugar, porque desde el punto de vista económico hay que tomar los recaudos analíticos necesarios al relacionar una variable flujo (PBI) con otra stock (deuda) y, en segundo lugar, porque ningún país podría destinar una vez y media su PBI para cancelar la deuda, como sucedía en Argentina en 2003. Por lo anterior, propongo analizar el "desendeudamiento" por medio de cinco variables: a) inflación; b) deuda soberana; c) reservas; d) desempleo, y f) asalariados sin cotización en el seguro social (en la Administración Nacional de la Seguridad Social de la República Argentina, en adelante ANSES). 
De esta forma, y tomando en cuenta el aporte realizado por Levine-Molina (2011a, 2011b), considero que la relación entre "deuda» y calidad de la democracia se puede presentar a través de las siguientes conexiones conceptuales: a menor endeudamiento mayor «autonomía económica» que se conecta positivamente con una mayor «soberanía» en las decisiones públicas, lo que resulta en un hecho valioso para la calidad de la democracia. La elección de las cinco variables responde al siguiente análisis. Para una sociedad con una larga experiencia inflacionaria e hiperinflacionaria, la inflación resulta relevante para la soberanía porque representa la confianza ciudadana en la moneda social. Las reservas son relevantes en términos de soberanía ya que su obtención, independientemente de fluctuaciones de los precios relativos, muestra la importancia de nuestros bienes y servicios en los mercados mundiales y la capacidad de respaldo a nuestra moneda social. El desempleo, para un país como Argentina, es muy relevante en términos de soberanía, puesto que la destrucción de empleo durante los años noventa del pasado siglo fue una de las causas que doxásticamente los ciudadanos le adjudican a la exclusión y desintegración social y política. En el mismo sentido se incorpora el trabajo informal, puesto que no goza de los beneficios de inclusión social y se le ha atribuido al mismo un gran poder de desintegración del tejido social. Estas variables no solo permiten analizar los cambios de un año a otro, sino también establecer una tendencia en el mediano y largo plazo. Tomadas en su conjunto son sensibles a los casos en que exista: a) un trade-off entre inflación y empleo (Curva de Phillips) y, también, b) para cuando se incrementan las reservas vía incremento de deuda.

En conjunto, las cinco variables muestran, como indica la tabla 1, las siguientes conexiones teóricas:

TABLA 1.

RELACIÓN CONCEPTUAL ENTRE LAS VARIABLES

\begin{tabular}{|c|c|c|c|c|c|c|}
\hline & & Inflación & $\begin{array}{c}\text { Deuda } \\
\text { Soberana }\end{array}$ & Reversas & Desempleo & $\begin{array}{c}\text { Asalariados } \\
\text { sin cotización } \\
\text { en ANSES }\end{array}$ \\
\hline $\begin{array}{l}\text { Mejoría en la } \\
\text { autonomía } \\
\text { económica, que } \\
\text { se traduce en }\end{array}$ & Mejora & Disminuye & Disminuye & Aumenta & Disminuye & Disminuye \\
\hline $\begin{array}{l}\text { una mayor } \\
\text { soberanía en las } \\
\text { decisiones } \\
\text { públicas. }\end{array}$ & Empeora & Aumenta & Aumenta & Disminuye & Aumenta & Aumenta \\
\hline $\begin{array}{l}\text { valorada } \\
\text { positivamente } \\
\text { en la calidad de } \\
\text { la democracia }\end{array}$ & $\begin{array}{c}\text { Sin } \\
\text { cambio }\end{array}$ & $\begin{array}{l}\text { Disminuye } \\
\text { (Aumenta) }\end{array}$ & $\begin{array}{c}\text { Aumenta } \\
\text { (Disminuye) }\end{array}$ & $\begin{array}{c}\text { Aumenta } \\
\text { (Disminuye) }\end{array}$ & $\begin{array}{c}\text { Aumenta } \\
\text { (Disminuye) }\end{array}$ & $\begin{array}{c}\text { Aumenta } \\
\text { (Disminuye) }\end{array}$ \\
\hline
\end{tabular}

Fuente: elaboración propia. 
Si la inflación y la deuda soberana descienden, las reservas aumentan, y si el desempleo y el trabajo sin cotización social descienden, podemos establecer conceptualmente que el «desendeudamiento» se relaciona con una mayor «autonomía económica» que, se supone, se traduce en una mayor soberanía en las decisiones públicas, suceso que se valora positivamente con una mejoría de la calidad de la democracia. Por otra parte, si a lo largo de un período, la inflación y la deuda soberana aumentan, las reservas disminuyen su nivel, el desempleo y el empleo no registrado aumentan, los datos nos indicarían que la observación sobre el «desendeudamiento» no generaría una mayor «autonomía económica», sino una menor autonomía que se traduciría en una menor capacidad soberana para tomar decisiones públicas, que se traduce en un empeoramiento de la calidad de la democracia. Si la inflación desciende (aumenta), la deuda soberana aumenta (disminuye), las reservas aumentan (disminuyen), el desempleo se incrementa (baja) y el trabajo sin cotización aumenta (baja) no resulta fácil establecer cómo se conecta el «desendeudamiento» con la «autonomía económica».

A continuación, en el gráfico 1 se muestra la evolución (entre 2003-2013) de las cinco variables. Se observa que a partir de 2007-2008 la deuda y la inflación comienzan a crecer, mientras que el desempleo y los asalariados sin cotización en ANSES (seguro social) continúan con una leve tendencia a la baja. Las reservas tienen un comportamiento errático, pero al final del período analizado se ubican por debajo del nivel existente en 2007 y $2008^{8}$.

Con los datos utilizados, se observa que entre 2003 y 2007-8 la inflación tiende a la baja, la deuda soberana disminuye, las reservas aumentan y el desempleo y el empleo no registrado disminuyen. En general, los datos indican que la observación sobre el «desendeudamiento» mejora la «autonomía económica». Se infiere de esto que mejora la soberanía para la toma de decisiones públicas y que este hecho puede usarse para generar una valoración positiva en el mejoramiento de la calidad de la democracia. Sin embargo, a partir del año 2008 la inflación tiende a subir, la deuda soberana se incrementa, las reservas tienen un comportamiento errático, mientras que el desempleo y el empleo no registrado descienden. Algo similar sucede si tomamos todo el período (2003-2014), en que se observa cómo la inflación aumenta, la deuda soberana disminuye para volver a aumentar acercándose a los valores iniciales, las reservas aumentan,

8. Todos los datos utilizados provienen del Instituto Nacional de Estadísticas y Censos de la República Argentina (INDEC). La mayoría de los analistas tuvieron una profunda desconfianza en los datos del INDEC. La línea de color rojo en el cuadro simboliza el punto de inflexión entre confianza y desconfianza pública sobre el accionar del INDEC. Para la mayoría de las consultoras especializadas, la inflación ha estado cercana al 25-30\% anual entre 20132105, y para algunos analistas el desempleo ha subido en el mismo período. He decidido en este estudio utilizar los datos oficiales por dos razones: a) mostrar que aún con los datos oficiales el impacto del desendeudamiento en la "autonomía económica» no resulta claro, y b) fundamentar cómo las estadísticas públicas, al integrar un conjunto de evidencias para la argumentación y el debate público, son parte del problema de la calidad de la democracia hacia finales del mandato presidencial de CFK (Avaro, 2016b). 


\section{GrÁFICO 1.}

SUBDIMENSIÓN DE LA DEUDA

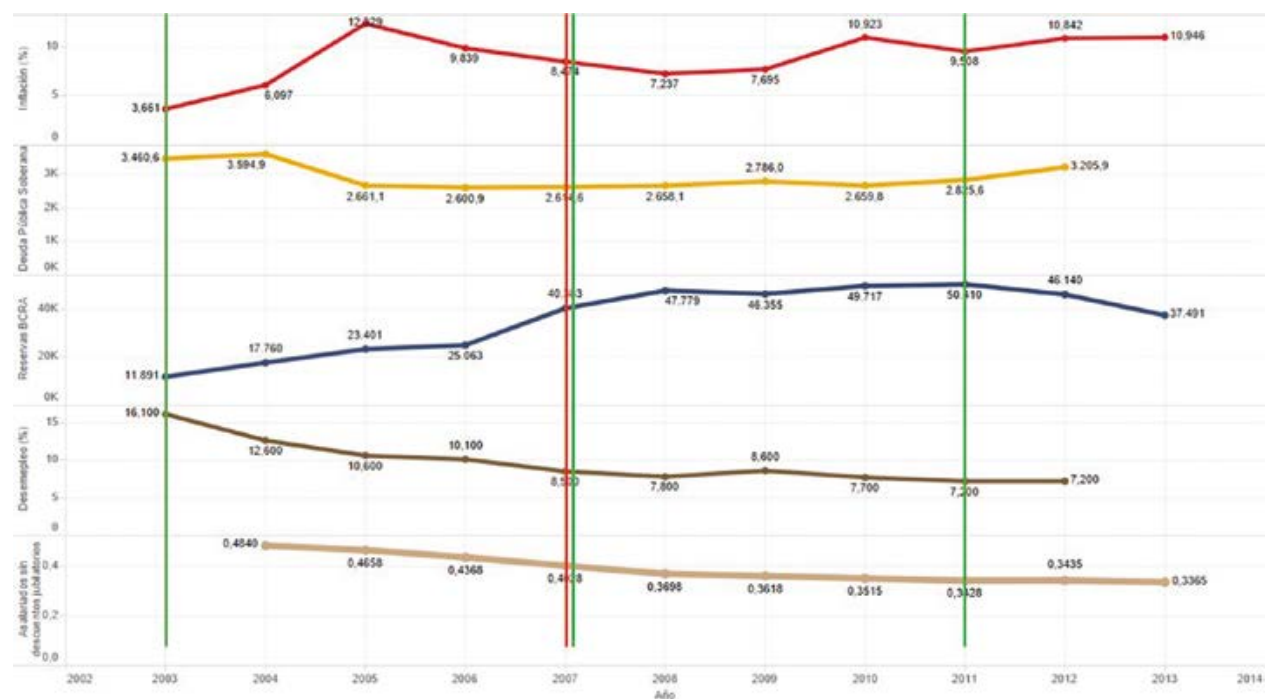

Nota: La línea roja denota que en enero de 2007 sucedió un cambio a nivel organizativo e institucional en el Instituto Nacional de Estadísticas y Censos de la República Argentina. Las líneas de color verde denotan las elecciones presidenciales $(2003,2007,2011)$.

Fuentes:

- Inflación. Serie histórica del Índice de Precios al Consumidor (IPC) en el Gran Buenos Aires con base abril de 2008=100. Datos disponibles en la web: https://goo.gl/v73EAU (consulta: 12 de enero 2015). Elaboración propia de acuerdo a datos y metodología establecida por el INDEC en: https://goo.gl/PAhqk1 (consulta: 12 de enero 2015).

- Deuda pública. Deuda pública de la República Argentina a valores constantes en millones de pesos, año base 1993. Período 2003-2014. Elaboración propia a partir de datos de CEPAL.

- Reservas del Banco Central de la República Argentina (BCRA). Datos del DBCRA. En millones de dólares estadounidenses, excluidas las Asignaciones DEG's 2009. Promedio anual.

- Desempleo. Datos del Banco Mundial. Desempleo total, como porcentual de la población activa total, estimación modelado OIT.

- Asalariados sin descuento jubilatorio. Encuesta Permanente de Hogares, INDEC. Calculada sobre el total asalariado.

el desempleo disminuye, al igual que los asalariados sin cotización en la seguridad social. Con estos datos no resulta posible establecer que el «desendeudamiento» mejoró la «autonomía económica», pero tampoco que la redujo; por tanto, la conexión analítica entre el «desendeudamiento» con la autonomía, y de esta con la mayor soberanía en la toma de decisiones públicas dificulta la comprensión de la responsividad como atributo positivo para con la calidad de la democracia.

Dado que los datos utilizados para «observar» el «desendeudamiento» muestran resultados ambiguos, es decir, que el analista no puede ni afirmar ni negar el impacto del "desendeudamiento» en la "autonomía económica», tampoco resulta posible afirmar (negar) que el hecho de que el Gobierno haya hecho lo que los 
ciudadanos deseaban y preferían generó un atributo positivo para la calidad de la democracia. Sin embargo, los ciudadanos convalidaron en dos elecciones presidenciales el sendero de responsividad trazado por la política de «desendeudamiento». De tal forma que: a) o bien el Gobierno implementó una política que los ciudadanos desean y prefieren, pero las variables utilizadas para observar el «desendeudamiento" no recogen la información pertinente, o bien b) omiten la dimensión «responsabilidad» al analizar el sendero de responsividad del «desendeudamiento», ya que no capturan las demandas de los diferentes públicos ciudadanos referidas a la ausencia de espacios y criterios para procesar los desacuerdos fácticos hacia el final del período analizado.

Si bien el sendero de responsividad, visibilizado en la legitimación de los desacuerdos doxásticos mediante dos elecciones presidenciales, nos dice que el Gobierno entre 2003-2014 hizo en materia de desendeudamiento lo que los ciudadanos deseaban y preferían, la prueba «observacional» utilizada muestra un punto de inflexión en 20072008, a partir del cual no se puede afirmar que el «desendeudamiento» ha empeorado la «autonomía económica» y que por ello disminuyó la soberanía decisional del Gobierno y que, por tanto, afectaría negativamente a la calidad de la democracia. Esto nos lleva a reflexionar en torno al por qué los diferentes públicos ciudadanos esperaron hasta el 2012-2014 para demandar mayor legitimidad en el procesamiento de los desacuerdos fácticos, niveles de institucionalidad para procesarlos, publicidad de los debates de los expertos, y el accionar del expertise en todos los actos autoritativos relacionados con el desendeudamiento. Se suele decir en estos casos que los ciudadanos convalidan orientación de políticas, no necesariamente resultados (Sánchez Cuenca, 2010), o bien que los resultados de las políticas se perciben con retardo, o que los ciudadanos no tienen episteme (solo doxa) para desentrañar los resultados de las políticas (Sartori, 1993; Downs, 1957; Pincione-Tesón, 2006). Sin embargo, no estamos analizando por qué los ciudadanos convalidan políticas, sino si la información que el analista recolecta permite vincular, al menos exploratoriamente, la relación entre responsividad, como atributo de la democracia, con la calidad de la misma. Lo que mostraré en el próximo epígrafe es que al introducir la legitimación de los desacuerdos fácticos tendremos oportunidad de ver este asunto de una manera más integral, aumentando la comprensión del fenómeno de la responsividad en los estudios de la calidad de la democracia.

\section{LA OFICINA NACIONAL DE CRÉDITO PÚBLICO Y LA LEGITIMACIÓN DE LOS DESACUERDOS FÁCTICOS}

En Argentina, desde el retorno de la democracia en 1983 hasta la actualidad, han mutado los desacuerdos doxásticos sobre el tópico de la deuda, como se espera en estos casos. Tales desacuerdos se legitiman a través de un proceso basal para la democracia como son las elecciones. Estas, al cerrar o definir (quién gobernará) y abrir (cómo se gobierna) (Rosanvallon, 2007), habilitan a que el proceso democrático le brinde 
visibilidad a la responsividad como bisagra entre lo que el Gobierno hace (políticas) y lo que la ciudadanía prefiere y desea (Page, 1994; Pennock, 1952; Powell, 2005). Sin embargo, es preciso advertir que los espacios y criterios de legitimación de los desacuerdos doxásticos no son los mismos que se utilizan para legitimar los desacuerdos de índole fáctica. El mecanismo de contar cabezas otorga legitimidad a los desacuerdos doxásticos, pero ello no es suficiente para legitimar los desacuerdos fácticos, ya que estos requieren otros espacios institucionales con sus respectivos criterios. ¿Cómo la democracia prevé los espacios institucionales (con sus respectivos criterios) para legitimar los actos autoritativos en torno a disputas fácticas, cuando aquellos son parte de la agenda democrática misma, i.e. a pesar de la existencia de desacuerdos doxásticos? Dicho de manera más específica y tomando el asunto de la deuda: ¿cómo la democracia prevé espacios institucionales para que los actos autoritativos del Gobierno permitan el ejercicio de la responsabilidad política, generando una sólida base para la rendición de cuentas y facilitando el diálogo democrático sobre los resultados de las políticas? Estas preguntas son cruciales porque permiten pensar que la legitimación de los desacuerdos fácticos resulta vital para la democracia.

El Congreso de la Nación Argentina previó este espacio al sancionar, en septiembre de 1992, la Ley 24 156, cuyo art. 5 creó, entre otros órganos rectores, la Oficina Nacional de Crédito Público para el Sistema de Crédito Público (ONCP) (arts. 68 y 69). La ONCP es un espacio institucional que el legislador diseñó para otorgarle relevancia al Estado (Poder Ejecutivo) en la centralización de las evidencias referidas a la deuda y sus usos retrospectivos, como así para la construcción de escenarios prospectivos. De tal forma, dota al Poder Ejecutivo de una plataforma institucional para procesar los desacuerdos fácticos, rendir cuentas y establecer diálogos informados entre los ciudadanos (Ley 24156 y Decreto 1361/94). Este espacio institucional, hasta 2015, se localizaba en la Secretaría de Finanzas del Ministerio de Economía y Finanzas Públicas y tiene un criterio identificable: la delegación por expertos, i.e. los ciudadanos, al elegir a los representantes, aceptan que estos designen a expertos que, a su vez, pueden designar a otros para legitimar los desacuerdos fácticos. Las razones que oportunamente tuvo el legislador para crear la ONCP, fueron: a) ordenar los registros de deuda, respaldar los archivos, centralizar la información y ordenarla como evidencia para la toma de decisiones autoritativas; b) transparentar las acciones de crédito público en la República Argentina, y c) propender a la coordinación de las políticas de endeudamiento del sector público.

$\mathrm{La} \mathrm{ONCP}$ es el espacio institucional para legitimar los desacuerdos fácticos porque tiene la función, acorde al espíritu que guía su creación, de dar respuesta a las preguntas que los diferentes públicos ciudadanos se realizaron entre 2012 y 2014: ¿cuánto debe Argentina? ¿A quién le debe? ¿Bajó o se mantuvo igual el endeudamiento soberano? ¿Podemos contratar nueva deuda? ¿Es sostenible el endeudamiento, en qué escenarios prospectivos? ¿A qué sectores y niveles del Estado le corresponde la deuda? ¿Qué niveles gubernamentales se han endeudado y por qué razones? Estas son las típicas preguntas que la ONCP tiene que contestar en los diálogos informados que los públicos ciudadanos mantienen entre sí. 
Dada la importancia de la ONCP para el proceso de legitimación que los diferentes y múltiples desacuerdos fácticos generados entorno al «desendeudamiento» (endeudamiento), expongo ahora, con el auxilio de la tabla 2, los criterios y subcriterios utilizados para analizar el funcionamiento de la ONCP. Estas dimensiones del análisis son tomadas del ordenamiento legal vigente, especialmente de la Ley 24156 y sus reglamentaciones, lo que permite contrastar el diseño institucional de la ONCP con su funcionamiento a lo largo de diceséis años.

TABLA 2.

IDENTIFICACIÓN DE CRITERIOS DE FUNCIONAMIENTO DE LA ONCP

\begin{tabular}{|c|c|c|c|c|}
\hline Período & $\begin{array}{c}\text { Espacio } \\
\text { institucional }\end{array}$ & $\begin{array}{c}\text { Criterio de } \\
\text { funcionamiento }\end{array}$ & $\begin{array}{l}\text { Criterios tomados } \\
\text { en cuenta para analizar } \\
\text { el funcionamiento } \\
\text { de la ONCP }\end{array}$ & Subcriterios \\
\hline \multirow{3}{*}{$\begin{array}{c}\text { Entre } \\
\text { 1996-2013 }\end{array}$} & \multirow{3}{*}{ Sí, ONCP } & \multirow{3}{*}{$\begin{array}{l}\text { Delegación } \\
\text { por expertos }\end{array}$} & $\begin{array}{l}\text { 1. Coordinación de } \\
\text { trámites, acciones y } \\
\text { políticas referidas al } \\
\text { endeudamiento del } \\
\text { Estado Nacional y sus } \\
\text { dependencias }\end{array}$ & $\begin{array}{l}\text { 1.1. Referencias en la } \\
\text { opinión pública sobre } \\
\text { el sistema de crédito } \\
\text { público } \\
\text { 1.2. Coordinación } \\
\text { de las propuestas } \\
\text { de financiamiento }\end{array}$ \\
\hline & & & $\begin{array}{l}\text { 2. Organización } \\
\text { sistemática de las } \\
\text { evidencias referidas a } \\
\text { los actos autoritativos } \\
\text { en materia de crédito } \\
\text { público }\end{array}$ & $\begin{array}{l}\text { 2.1. Organizar } \\
\text { información para } \\
\text { transparentar las } \\
\text { operatorias de crédito } \\
\text { público }\end{array}$ \\
\hline & & & $\begin{array}{l}\text { 3. Registro público } \\
\text { de deuda, información } \\
\text { retrospectiva y } \\
\text { planeaciones } \\
\text { prospectiva }\end{array}$ & $\begin{array}{l}\text { 3.1. Registrar y } \\
\text { mantener actualizadas } \\
\text { las operatorias de } \\
\text { deuda pública. } \\
\text { 3.2. Fiscalizar. } \\
\text { 3.3. Hacer } \\
\text { proyecciones }\end{array}$ \\
\hline
\end{tabular}

Fuente: elaboración propia a partir de la Ley 24156.

Para examinar el subcriterio 1.1 se procedió a analizar la importancia de la ONCP en la opinión publicada, por lo que se contabilizó la frecuencia de aparición de la ONCP en dos de los principales diarios argentinos de alcance nacional durante el período 19982014. Si la ONCP tiene un rol preponderante como referente del sistema de crédito público del Estado argentino, debería reflejarse en la opinión publicada. Para el subcriterio 1.2 se analizó la relación de la ONCP con otras oficinas gubernamentales y sus 
particularidades. Si la ONCP tiene la responsabilidad de coordinar las propuestas de financiamiento del sector público, debería estar reflejado en legislación vigente. Para ello, se utilizaron como fuentes informativas el marco legal vigente (Ley 24 156, Decreto 1361/94, Decreto 1359/04, Resolución 29/2011) y el Informe Anual 2009 de la AGN. Para analizar el resto de los subcriterios se utilizaron los informes anuales de la AGN.

Para analizar qué relevancia tuvo la ONCP en la opinión pública cuando esta trataba la deuda como asunto público, analicé la frecuencia con la que ha aparecido la ONCP en dos de los principales diarios argentinos de circulación nacional (gráfico 2). En todo el período analizado (1998-2014), si bien se observa que en general la ONCP ha aparecido con poca frecuencia (cincuenta veces en dieciséis años), se convierte en noticia, como resulta esperable, en momentos de máxima tensión política y de conflicto económico, pero también resalta que el rol atribuido a esta en lo atinente a coordinación del financiamiento público es difuso y en cierta manera secundario a otros actores gubernamentales. Por tanto, la visibilización de la ONCP en la opinión pública es escasa y su accionar se presenta de manera difusa.

\section{GrÁFICO 2.}

Oficina Nacional de Crédito Público en la opinión publicada

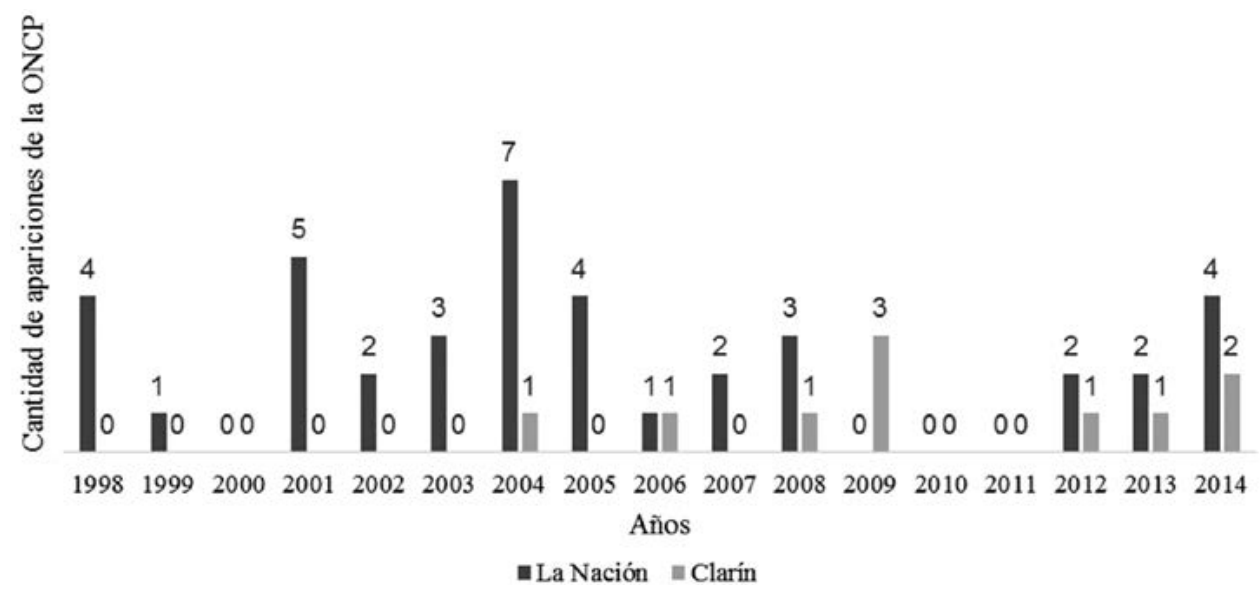

Fuente: elaboración propia a partir de datos del diario La Nación, obtenidos de: http://buscar.lanacion.com.ar/ediciones\%20anteriores [período de búsqueda: 1995-2014]; y a partir del diario Clarín, obtenidos de: http://edant.clarin. com/edicant.html [período de búsqueda: 1997-2014].

Consideremos ahora el subcriterio 1.2. La ONCP, para convertirse en «órgano rector» del sistema de crédito público, de acuerdo a la Ley 24156 y al Decreto 1361/94, tiene que desarrollar actividades de coordinación tendentes a sistematizar información y evidencias con la finalidad de propender a la elaboración de políticas. La tabla 3 muestra la compleja relación entre oficinas y niveles del, por entonces, Ministerio de Economía y Finanzas Públicas, el Tesoro Nacional y otros organismos públicos vigente hasta diciembre de 2015. 
TABLA 3.

ENTRAMADO DE INTERACCIONES GUBERNAMENTALES QUE RESTRINGEN EL ROL DE LA ONCP

\begin{tabular}{|c|c|}
\hline $\begin{array}{l}\text { Actores Públicos } \\
\text { Institucionales }\end{array}$ & Particularidades de la relación \\
\hline $\begin{array}{l}\text { Secretaría } \\
\text { de } \\
\text { Finanzas }\end{array}$ & $\begin{array}{l}\text { La ONCP es la responsable de ejercer, junto con la Secretaría de } \\
\text { Finanzas y la Secretaría de Hacienda, las funciones de órgano respon- } \\
\text { sable de la Coordinación de los Sistemas de Administración Finan- } \\
\text { ciera del Sector Público Nacional. Además, la Secretaría de Finanzas } \\
\text { mantiene otras relaciones que influyen en el accionar de la ONCP, a } \\
\text { saber: a) se encarga de la coordinación de los aspectos administrativos } \\
\text { de las relaciones del BCRA, del Banco de la Nación Argentina, del } \\
\text { Banco de Inversión y Comercio Exterior SA y del Banco Hipotecario } \\
\text { SA con el Poder Ejecutivo Nacional; b) interviene en las negociacio- } \\
\text { nes inherentes al tema con entes financieros nacionales, extranjeros, } \\
\text { públicos, privados y el FMI, tomando a su cargo las relaciones con la } \\
\text { comunidad financiera internacional y la coordinación de las repre- } \\
\text { sentaciones en el exterior, y c) coordina las relaciones entre la Comi- } \\
\text { sión Nacional de Valores, la Superintendencia de Seguros de la } \\
\text { Nación y el Poder Ejecutivo Nacional. }\end{array}$ \\
\hline $\begin{array}{l}\text { Secretaría } \\
\quad \text { de } \\
\text { Hacienda }\end{array}$ & $\begin{array}{l}\text { La ONCP es la responsable de ejercer, junto con la Secretaría de } \\
\text { Finanzas y la Secretaría de Hacienda, las funciones de órgano res- } \\
\text { ponsable de la Coordinación de los Sistemas de Administración } \\
\text { Financiera del Sector Público Nacional. Por otro lado, la ONCP } \\
\text { debe elaborar informes de cierre contable con la frecuencia que las } \\
\text { normas de la Contaduría General de la Nación, dependiente de la } \\
\text { Subsecretaría de Presupuesto de la Secretaría de Hacienda, lo } \\
\text { determinen. }\end{array}$ \\
\hline $\begin{array}{l}\text { Subsecretaría } \\
\text { de } \\
\text { Servicios Financieros }\end{array}$ & $\begin{array}{l}\text { La ONCP recibe asistencia con respecto a la elaboración de propues- } \\
\text { tas que promuevan la armonización y coordinación de las normas que } \\
\text { involucran a los distintos servicios financieros, acordes con la realidad } \\
\text { del mercado y las tendencias internacionales. }\end{array}$ \\
\hline $\begin{array}{l}\text { Administración } \\
\text { Central, Organismos } \\
\text { Descentralizados y } \\
\text { Empresas y } \\
\text { Sociedades del Estado }\end{array}$ & $\begin{array}{l}\text { Supervisar la correcta operatividad de la contabilidad analítica de sus } \\
\text { deudas públicas internas y externas. }\end{array}$ \\
\hline Tesoro Nacional & $\begin{array}{l}\text { Supervisar las actividades vinculadas con la gestión, seguimiento y } \\
\text { registro de los avales que emita el Tesoro Nacional, dentro del marco } \\
\text { de la legislación vigente. }\end{array}$ \\
\hline
\end{tabular}

Fuente: Elaboración propia (Ley 24 156, Decreto 1361/94, Decreto 1359/04, Resolución 29/2011).

La AGN señala, en el Informe Anual 2009, en un sentido negativo, la existencia de un entramado de decretos que favorece la falta de coordinación entre niveles y oficinas 
(AGN, 2009: 19). Este entramado normativo impide, a juicio de la AGN (2009: 22), delimitar las responsabilidades entre oficinas gubernamentales del Poder Ejecutivo Nacional. A modo ejemplificativo: el Decreto 67/03 le otorga a la Secretaría de Finanzas la capacidad de ejecutar políticas y medidas sobre aspectos crediticios; también el Decreto 67/03 faculta a la Secretaría de Política Económica coordinar las negociaciones con los organismos financieros internacionales de crédito, y el Decreto 624/03 señala como tareas de la Jefatura de Gabinete de Ministros de la República Argentina coordinar, evaluar y controlar las prioridades en la gestión del financiamiento externo (AGN, 2009: 22). Todo ello soslayando que se encuentra en vigencia la Ley 24156 que en su art. 68 establece que la ONCP «es el órgano rector del Sistema de Crédito Público».

TABLA 4.

AUdiTORÍA GENERAL DE LA NACIÓN: OBSERVACIONES QUE INVOLUCRAN A LA ONCP

\begin{tabular}{|c|c|c|c|}
\hline $\begin{array}{l}\text { Informe } \\
\text { / año }\end{array}$ & $\begin{array}{l}\text { Mención directa } \\
\text { de la ONCP }\end{array}$ & $\begin{array}{l}\text { Recomendación, análisis, } \\
\text { sugerencias, inconsistencias } \\
\text { detectadas referidas al } \\
\text { funcionamiento de la ONCP }\end{array}$ & $\begin{array}{l}\text { Recomendación, análisis, } \\
\text { sugerencias, inconsistencias } \\
\text { detectadas referidas al } \\
\text { funcionamiento de la ONCP sin } \\
\text { mención directa a la Oficina }\end{array}$ \\
\hline 1996 & No se encontraron & No se detectaron & Si \\
\hline 1997 & No se encontraron & No se detectaron & $\mathrm{Si}$ \\
\hline 1998 & $\mathrm{Si}$ & $\mathrm{Si}$ & $\mathrm{Si}$ \\
\hline 1999 & No se encontraron & $\mathrm{Si}$ & $\mathrm{Si}$ \\
\hline 2000 & $\mathrm{Si}$ & $\mathrm{Si}$ & $\mathrm{Si}$ \\
\hline 2001 & $\mathrm{Si}$ & $\mathrm{Si}$ & $\mathrm{Si}$ \\
\hline 2002 & No se encontraron & No se encontraron & No se encontraron \\
\hline 2005 & No se encontraron & No se encontraron & $\mathrm{Si}$ \\
\hline 2006 & No se encontraron & No se encontraron & Si \\
\hline 2007 & No se encontraron & No se encontraron & No se encontraron \\
\hline 2008 & No se encontraron & No se encontraron & No se encontraron \\
\hline 2009 & $\mathrm{Si}$ & $\mathrm{Si}$ & $\mathrm{Si}$ \\
\hline 2010 & No se encontraron & No se encontraron & No se encontraron \\
\hline 2011 & $\mathrm{Si}$ & $\mathrm{Si}$ & $\mathrm{Si}$ \\
\hline 2012 & Si & $\mathrm{Si}$ & $\mathrm{Si}$ \\
\hline 2013 & No se encontraron & No se encontraron & No se encontraron \\
\hline
\end{tabular}

Fuente: elaboración propia en base a los Informes Anuales de la AGN.

Así, con un abigarramiento legal que no favorece las actividades de coordinación entre la ONCP y las demás áreas gubernamentales, aunado a la superposición de tareas, se ha generado un entramado institucional que no promueve el rol «rector», atribuido 
originalmente por el legislador a la ONCP en materia de coordinación del financiamiento del sector público argentino. A su vez, observando en conjunto el diagnóstico evaluativo realizado por la AGN y la escasa visibilidad de la ONCP en la opinión publicada, parece reforzarse la idea de que el rol «rector» de la ONCP en el sistema de crédito público argentino es subsidiario o complementario de otros actores gubernamentales con más peso decisorio.

En la tabla 4 se analizan los Informes Anuales de la AGN (1996-2003) con la intención de obtener información sobre los demás criterios de funcionamiento de la ONCP. Dicho análisis se concentró en lo siguiente: a) cuántas veces aparece de manera directa la ONCP en los informes y auditorías realizadas durante el período 1996-2013; b) en caso de ser mencionada, en qué contexto aparece; c) qué tipo de descripción se hace de la ONCP, y, finalmente, d) si la AGN realiza alguna recomendación, de qué tipo, y si se indican sugerencias de revisiones y seguimientos, de qué naturaleza son.

De un total de dieciséis Informes Anuales, la AGN dedicó en seis de ellos una sección específica a la ONCP. En siete se realizan recomendaciones en forma directa a la ONCP. En once hay recomendaciones de manera indirecta a la ONCP, es decir, por el análisis de otros actores gubernamentales que por su interacción realizan actividades o se vinculan con la ONCP. En la tabla 5 se describen las observaciones realizadas por la AGN para cada criterio y subcriterio.

TABLA 5.

Debilidades de La ONCP COMO ESPACIO INSTITUCIONAL ENCARGADO DE PROCESAR DESACUERDOS FÁCTICOS

ONCP como Espacio institucional encargado

de procesar desacuerdos fácticos

Período $\begin{gathered}\text { Criterios tomados en } \\ \begin{array}{c}\text { cuenta para analizar } \\ \text { el funcionamiento de } \\ \text { la ONCP }\end{array}\end{gathered}$

\begin{tabular}{|c|c|c|c|}
\hline 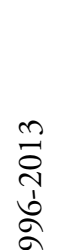 & $\begin{array}{l}\text { 1. Coordinación de } \\
\text { trámites, acciones y } \\
\text { políticas referidas al } \\
\text { endeudamiento del } \\
\text { Estado Nacional y } \\
\text { sus dependencias }\end{array}$ & $\begin{array}{l}\text { 1.1. Referente a la } \\
\text { opinión publicada } \\
\text { sobre el sistema de } \\
\text { crédito público }\end{array}$ & $\begin{array}{l}\text { La ONCP tiene una débil presencia en } \\
\text { la opinión publicada. De allí se infiere } \\
\text { que tiene una escasa presencia en la } \\
\text { opinión pública. No está retratada } \\
\text { como el «órgano referente» en materia } \\
\text { de endeudamiento }\end{array}$ \\
\hline$\underset{\Xi}{\stackrel{ \pm}{ \pm}}$ & & $\begin{array}{l}\text { 1.2. Coordinación } \\
\text { de las propuestas de } \\
\text { financiamiento }\end{array}$ & $\begin{array}{l}\text { Los datos muestran que lejos de obte- } \\
\text { ner una coordinación hay una incoor- } \\
\text { dinación entre diferentes agencias y } \\
\text { niveles gubernamentales en materia de } \\
\text { crédito público }\end{array}$ \\
\hline
\end{tabular}




\begin{tabular}{lll} 
N..... & \multicolumn{2}{c}{$\begin{array}{c}\text { ONCP como Espacio i } \\
\text { de procesar desa }\end{array}$} \\
\cline { 2 - 3 } Período & $\begin{array}{l}\text { Criterios tomados en } \\
\text { cuenta para analizar } \\
\text { el funcionamiento de } \\
\text { la ONCP }\end{array}$ & \multicolumn{1}{c}{ Subcriterios } \\
\hline & $\begin{array}{l}\text { 2. Organización } \\
\text { sistemática de las } \\
\text { evidencias referidas } \\
\text { a los actos } \\
\text { autoritativos en } \\
\text { materia de crédito } \\
\text { público }\end{array}$ & $\begin{array}{l}\text { 2.1. Organizar } \\
\text { información para } \\
\text { transparentar las } \\
\text { operatorias de } \\
\text { crédito público }\end{array}$ \\
\hline
\end{tabular}

Los datos analizados dan cuenta de problemas de integración entre los diferentes softwares de registro de datos de deuda. Una integración parcial entre el software Sistema de Gestión y Análisis de la Deuda (SIGADE) provisto por la Conferencia de las Naciones Unidas sobre el Comercio y Desarrollo (UNCTAD) con el Sistema Integrado de Información Financiera para Organismos Descentralizado (SIDIF) genera errores de registro del principal (capital) y los intereses

\begin{tabular}{|c|c|c|}
\hline \multirow[t]{3}{*}{$\begin{array}{l}\text { 3. Registro público } \\
\text { de deuda, } \\
\text { información } \\
\text { retrospectiva y } \\
\text { planeaciones } \\
\text { prospectiva }\end{array}$} & $\begin{array}{l}\text { 3.1. Registrar y } \\
\text { mantener } \\
\text { actualizadas las } \\
\text { operatorias de } \\
\text { deuda pública }\end{array}$ & $\begin{array}{l}\text { Los datos analizados muestran que la } \\
\text { falta de integración en los sistemas regis- } \\
\text { trables son problemas de larga data, no } \\
\text { se han solucionado a pesar de las insis- } \\
\text { tentes recomendaciones de la AGN y } \\
\text { generan efectos negativos en la operato- } \\
\text { ria de la deuda }\end{array}$ \\
\hline & 3.2. Fiscalizar & $\begin{array}{l}\text { La información analizada realiza reco- } \\
\text { mendaciones expresas sobre la imple- } \\
\text { mentación de manuales de operación, } \\
\text { con el objetivo de ajustarse a las buenas } \\
\text { prácticas y a los estándares internacio- } \\
\text { nales en la materia }\end{array}$ \\
\hline & $\begin{array}{l}\text { 3.3. Hacer } \\
\text { proyecciones }\end{array}$ & $\begin{array}{l}\text { Las observaciones de los informes dis- } \\
\text { ponibles en el sitio de la Secretaría de } \\
\text { Finanzas del Ministerio de Economía y } \\
\text { Finanzas Públicas de la República } \\
\text { Argentina dan cuenta de proyecciones, } \\
\text { pero no de escenarios. El único análisis } \\
\text { de escenarios disponible al público ciu- } \\
\text { dadano es el proporcionado por la } \\
\text { AGN (2005) en un informe específico } \\
\text { sobre la "deuda» }\end{array}$ \\
\hline
\end{tabular}

Fuente: elaboración propia a partir de los Informes Anuales de la AGN, años 1996-2013. 
El análisis de los criterios de funcionamiento muestra un conjunto de debilidades de carácter estructural en el interior de la ONCP. Entre las debilidades detectadas cabe destacar: a) debilidad para coordinar las políticas de financiamiento del sector público; b) insuficiente capacidad para integrar sistemas registrables alternativos, aunado a la falta de manuales de operación que se ajusten a las normas y prácticas internacionales, y finalmente c) no se visualiza a la ONCP como el órgano rector o integrador de las políticas de financiamiento del sector público argentino.

Dada la descripción realizada sobre el funcionamiento de la ONCP, resulta ahora algo más comprensible que cuando los diferentes públicos que conforman la opinión pública argentina preguntan sobre el «estado» de la deuda y del endeudamiento encuentran una variedad disímil de respuestas. Quizá no encuentran en la ONCP el espacio institucional que procesa y legitima los desacuerdos fácticos porque su funcionamiento real: a) no está orientado a rendir cuentas; b) no sistematiza información para la reflexión de los diferentes públicos ciudadanos; c) su capacidad para intervenir en los debates públicos es escasa; d) su capacidad para ofrecer certezas sobre la necesidad y capacidad de financiamiento del sector público es mínima, y finalmente d) su rol en la provisión de prospectivas está ausente en los debates públicos.

\section{CONCLUSIONES}

$\mathrm{Al}$ inicio de este trabajo formulé la siguiente pregunta: ¿cómo opera la responsabilidad en los casos en que la responsividad no parece conflictiva o anómala para la teoría democrática? Expresado de forma más específica: ¿cómo interviene la responsabilidad en los casos en que hacer lo que los ciudadanos desean y prefieren parece, intuitivamente desde la teoría, una situación de mejora en la calidad de la democracia?

Para indagar esta cuestión abordé el proceso de «desendeudamiento» llevado a cabo por el Gobierno argentino entre 2003 y 2014. Introduje en la red conceptual responsividad la responsabilidad mediante los asuntos etiquetados como «desacuerdos fácticos», lo que permitió ensanchar la base informacional en el análisis de la responsividad. El análisis realizado no solo recoge información sobre la legitimación de los desacuerdos doxásticos, sino, también, incorpora la capacidad institucional del Estado para que el Gobierno procese y legitime los desacuerdos fácticos. Al incorporar los desacuerdos fácticos en el concepto de responsividad, sobre todo a partir de la identificación del nivel institucional para procesar desacuerdos, los criterios de designación de expertos y funcionamientos, obtenemos una descripción más densa de cómo opera la responsividad; ya no solo legitimando los desacuerdos doxásticos, sino también de cómo operan las capacidades institucionales disponibles para procesar los desacuerdos fácticos en la democracia. En el diagrama 1 se muestra la ruta crítica del análisis realizado.

Asumiendo que la responsividad es un atributo valioso para la calidad de la democracia, y siguiendo trabajos previos, analicé el «desendeudamiento» argentino a 
Diagrama 1.

RUTA CRÍtICA SOBRE LA EXPERIENCIA DEL DESENDEUDAMIENTO ARGENTINO (2003-2014)

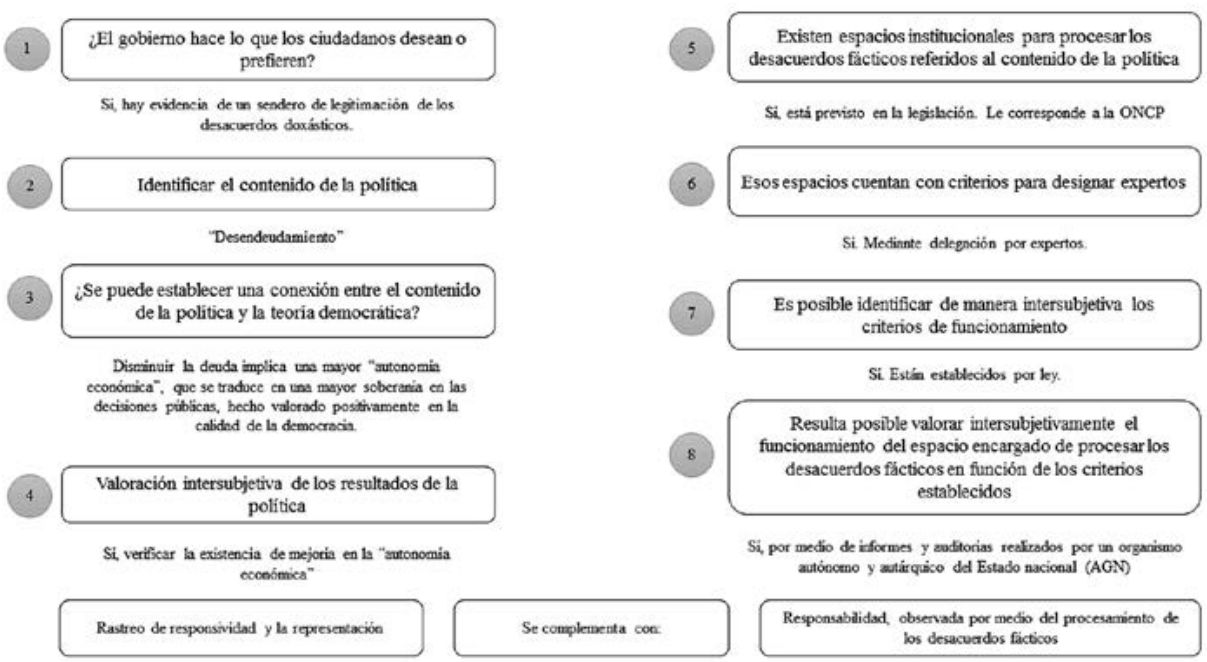

Fuente: elaboración propia.

partir de la siguiente conexión teórica: la reducción de la «deuda» implica una mayor «autonomía económica», y esta se vincula de manera directa con una mayor autonomía en las decisiones públicas, hecho que se valora positivamente para la calidad de la democracia. En un primer momento, conforme a los datos oficiales examinados para el período 2003-2013, si utilizamos la relación deuda/PBI se advierte mayor «autonomía económica». Así, mediante la observación de la relación deuda/PBI nada impide que el analista vincule el «desendeudamiento» con la calidad de la democracia mediante la existente de la responsividad: el Gobierno reduce la deuda, demanda preferida y deseada por los ciudadanos y convalidada en dos elecciones presidenciales. Explicitadas las limitaciones de esa relación para el caso argentino, procedí, en un segundo momento, a indagar los resultados del «desendeudamiento» por medio de cinco variables. Tomando el mismo período ya no queda claro que se haya producido una mayor "autonomía económica». Sin embargo, el analista no puede afirmar, con esos datos, que el Gobierno no hacía lo que los ciudadanos deseaban y preferían. En este caso no resulta tarea sencilla relacionar la responsividad con la calidad de la democracia. Y como ya mencioné, los diferentes públicos que conforman la opinión pública argentina demandaban, hacia el final del mandato presidencial de CFK, mayor claridad en la medición del endeudamiento argentino, mientras el instrumento utilizado no estaba recogiendo esa información. En un tercer momento, procedí a ensanchar la base informacional de la responsividad mediante la incorporación de los desacuerdos fácticos. Lo hice mediante el análisis del 
funcionamiento de la ONCP. Los resultados muestran un deficiente rol de la ONCP como organismo rector del sistema de financiamiento del sector público argentino. En el diagrama 2 se resume el trabajo realizado.

A partir del trabajo realizado extraigo dos conclusiones en dos niveles diferentes:

1. Tomando en cuenta el caso del «desendeudamiento» argentino, no se puede afirmar que la «autonomía económica» haya mejorado, y que con esta se haya producido una mayor soberanía en las decisiones públicas. Esto implica que aún en el caso en donde el Gobierno hace lo que los ciudadanos desean y prefieren, no resulta que este hecho se pueda valorar positivamente en la mejoría de la calidad de la democracia, y ello, en el caso de análisis, porque el manejo de los desacuerdos fácticos dista mucho de los criterios básicos y mínimos requeridos para una democracia comprometida con la discusión pública, la prueba intersubjetivamente validada y la rendición de cuentas.

2. Si bien la responsividad es un atributo de la democracia valorado positivamente en su calidad, su existencia no se traduce siempre en un hecho valioso para la calidad de la democracia. La prueba que tiene que superar, para que ello suceda, es que la responsabilidad se encuentre presente en la respuesta política del Gobierno. De esta forma, la responsabilidad interviene no solo en los casos en donde la no-responsividad parece ser la mejor alternativa a la disminución de la calidad de la democracia, sino, principalmente, en aquellos casos en donde hacer lo que los ciudadanos desean y prefieren parece ser, dadas nuestras creencias e intuiciones teóricas, la mejor forma de mejorar la calidad de la democracia.

Diagrama 2.

ANÁlisis DE LA EXPERIENCIA DEL DESENDEUDAMIENTO ARGENTINO (2003-2014)
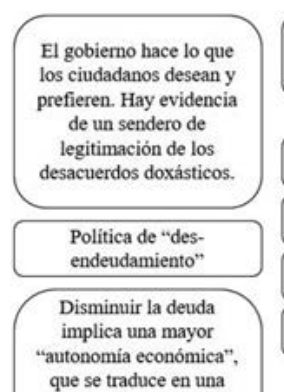

que se traduce en una

mayor soberania en las

decisiones públicas,

hecho valorado

positivamente en la

calidad de la

democracia.
Verificación de la existencia de mejoria en la "autonomia económica"

\begin{tabular}{|c|c|c|c|c|c|c|c|c|}
\hline Periodo & $\begin{array}{c}\text { Tipo de } \\
\text { medición }\end{array}$ & $\begin{array}{c}\text { Mejoró la "autonomia } \\
\text { económica" }\end{array}$ \\
\hline $\begin{array}{c}2003- \\
2012\end{array}$ & $\begin{array}{c}\text { Deuda } \\
\text { PBI }\end{array}$ & Mejoró \\
\hline $\begin{array}{c}2003- \\
2007 / 8\end{array}$ & $\begin{array}{c}\text { Análisis } \\
\text { de las } \\
\text { cinco } \\
\text { variables }\end{array}$ & Mejoró \\
\hline $2003-$ & No mejoró \\
\hline
\end{tabular}

Evaluación de los criterios utilizados para procesar los desacuerdos fácticos

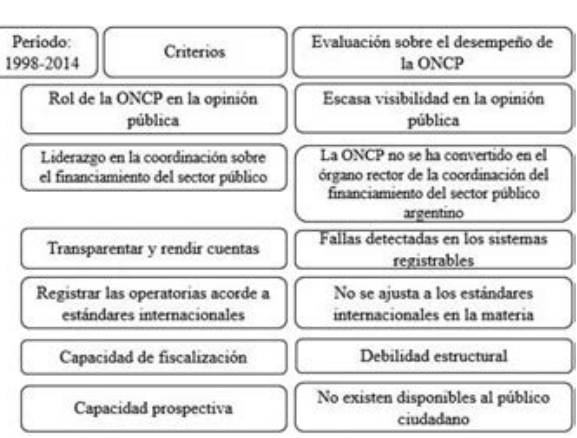

Fuente: elaboración propia. 


\section{AGRADECIMIENTOS}

Quiero agradecer las críticas, comentarios y sugerencias de los evaluadores anónimos y de los editores de la Revista Española de Ciencia Política. Estoy en deuda por la lectura atenta y los comentarios de Carlos Sánchez, Carlos Moreira y Pablo Stropparo.

\section{Referencias}

Aguilar Villanueva, Luis. 2007. «Estudio introductorio», en El Estudio de las Políticas Públicas, tomo I. Ciudad de México: Miguel Ángel Porrúa.

Avaro, Dante. 2014. «Argentina: deuda externa y democracia». Disponible en: http:// www.7tres.com/?p=1150 [consulta: 24-1-2017].

Avaro, Dante. 2015. «Responsiveness. Discusión analítica y conceptual para su utilización en la agenda de la calidad de la democracia», en Dante Avaro y Carlos Sánchez y Sánchez (eds), Calidad de la democracia y respuesta politica. Responsiveness. Ciudad de México: Senado de la República y Grañón Porrúa.

Avaro, Dante. 2016a. «Políticas, desacuerdos fácticos y calidad de la democracia: una revisión de la dimensión de resultados», en Lídia Oliveira Xavier y Carlos Domínguez Avila (eds), A qualidade da democracia no Brasil: Questoes teóricas e metodológicas da pesquisa, vol. 1. Curitiva: Editora CRV.

Avaro, Dante. 2016b. «Democracia y desacuerdos fácticos: ¿procesarlos o eliminarlos? Una aproximación desde 'acontecimiento INDEC'», Revista Andamios, 13 (30): 63-81.

Bardi, Luciano, Stefano Bartolini y Alexander Trechsel. 2014. «Responsive and responsible? The role of parties in Twenty-First Century», West European Politics, 1 (2): 235-252. Disponible en: https://doi.org/10.1080/01402382.2014.887871.

Cejudo, Guillermo, Gilberto Sánchez y Dionisio Zabaleta. 2009. «El (casi inexistente) debate conceptual sobre la calidad del gobierno», Politica y Gobierno, 16 (1): 115-156.

Dahl, Robert. 1972. Polyarchy: Participation and opposition. New Haven: Yale University Press.

Donovan, Florencia. 2014. «El gobierno permitió la mayor devaluación del peso en 12 años». Buenos Aires: Diario La Nación. Disponible en: http://goo.gl/9leJ2F [consulta: 20-5-2015].

Downs, Anthony. 1957. An economic theory of democracy, New York: Harper and Row. Erikson, Robert. 2013. «Policy responsiveness to public opinion», Oxford Bibliographies Online:PoliticalScience.Disponibleen:https://doi.org/10.1093/obo/9780199756223.

Kappel, Klemens. 2014. «Factual disagreement and political legitimacy», en Catherine Holst (ed), Expertise and Democracy. Arena Report 1.

Kraay, Aart, Daniel Kaufmann y Massimo Mastruzzi. 2010. "The worldwide governance indicators methodology and analytical issues», World Bank Policy Research Working Paper, 5430. Disponible en: https://doi.org/10.1596/1813-9450-5430. 
Levine, Daniel y José Enrique Molina. 2011a. «Calidad de la democracia: fortalezas y debilidades en América Latina», Revista Latinoamericana de Politica Comparada, 5: 95-123.

Levine, Daniel y José Enrique Molina. 2011b. The quality of democracy in Latin American. Boulder (CO): Lynne Rienner.

Linz, Juan. José. 2009. Democracias: quiebras, transiciones y retos. Vol. 4. Madrid: Centro de Estudios Políticos y Constitucionales.

Mair, Peter. 2009. «Representative versus responsible Government», MPIfG Working Papers, 8. Colonia: Max Planck Institute for the Study of Societies.

Mair, Peter. 2015. Gobernando el vacio. La banalización de la democracia occidental. Madrid: Alianza.

Morlino, Leonardo. 2004a. "What is a 'good' democracy?», Democratization, 11 (5): 10-32. Disponible en: https://doi.org/10.1080/13510340412331304589.

Morlino, Leonardo. 2004b. «Good and bad democracies: How to conduct research into the quality of democracy», Journal of Communist Studies and Transition Politics, 20 (1): 5-27. Disponible en: https://doi.org/10.1080/13523270410001687082.

Morlino, Leonardo, Juan Rial y Manuel Alcántara. 2014. La calidad de las democracias en América Latina. Informe para IDEA Internacional. Nueva York: IDEA.

Munck, Gerardo. 2006. «Monitoreando la democracia. Profundizando un consenso emergente», Revista de Ciencia Politica, 26 (1): 158-168. Disponible en: https:// doi.org/10.4067/s0718-090x2006000100010.

Munck, Gerardo. 2011. «Los estándares de la democracia: hacia una formulación de la cuestión democrática en América Latina», Journal of Democracy en español, 3: 22-41.

Munck, Gerardo y Jay Verkuilen. 2002. "Conceptualizing and measuring democracy: Evaluating alternative indices», Comparative Political Studies, 35 (1): 5-34. Disponible en: https://doi.org/10.1177/001041400203500101.

Page, Benjamin I. 1994. "Democratic responsiveness? Untangling the links between public opinion and policy", Political Science and Politics, 27 (1): 25-29. Disponible en: https://doi.org/10.1017/S1049096500039834.

Pennock, James R. 1952. "Responsiveness, responsibility, and majority rule», American Political Science Review, 46 (3): 790-807. Disponible en: https://doi. org/10.2307/1952285.

Pincione, Guido y Fernando R. Tesón. 2006. Rational choice and democratic deliberation: A theory of discourse failure. Cambridge: Cambridge University Press. Disponible en: https://doi.org/10.1017/CBO9780511720178.

Pitkin, Hanna F. 1967. The concept of representation. Berkeley and Los Angeles: University of California Press.

Powell, G. Bingham. 2004. «The quality of democracy: The chain of responsiveness», Journal of Democracy, 15 (4): 91-105. Disponible en: https://doi.org/10.1353/ jod.2004.0070.

Powell, G. Bingham. 2005. «The Chain of Responsiveness», en Larry Diamond y Leonardo Morlino (coords.), Assessing the quality of democracy. Baltimore: John Hopkins University Press. 
Przeworski, Adam. 1997. «Una defensa de la concepción minimalista de la democracia", Revista Mexicana de Sociología, 59 (3): 3-36. Disponible en: https://doi. org/10.2307/3541371.

Przeworski, Adam. 2010. Qué esperar de la democracia. Limites y posibilidades del autogobierno. Buenos Aires: Siglo XXI Editores.

Rogoff, Keneth y Carmen Reinhart. 2011. This time is different: Eight centuries of financial folly. Princeton (NJ): Princeton University Press.

Rosanvallon, Pierre. 2007. La contrademocracia: la política en la era de la desconfianza, Buenos Aires: Manantial.

Sánchez Cuenca, Ignacio. 2010. Más democracia, menos liberalismo. Madrid: Katz Editores.

Sartori, Giovanni. (1993). Qué es la democracia. México DF: Tribunal Electoral Federal.

Schumaker, Paul D. 1975. «Policy responsiveness to protest-group demands», The Journal of Politics, 37 (2): 488-521. Disponible en: https://doi.org/10.1017/ S0022381600041256.

Stimson, James, Michael Mackuen y Robert Erikson. 1995. «Dynamic representation», The American Political Science Review, 89 (3): 543-565. Disponible en: https://doi.org/10.2307/2082973.

Vidal de la Rosa, Godofredo (2015). «Political responsiveness en la ciencia política estadounidense», en Dante Avaro y Carlos Sánchez y Sánchez (eds), Calidad de la democracia y respuesta politica. Responsiveness. Ciudad de México: Senado de la República y Grañón Porrúa.

Wlezien, Christopher. 2005. "On the salience of political issues: The problema with 'most important problem'», Electoral Studies, 24 (4): 555-579. Disponible en: https://doi.org/10.1016/j.electstud.2005.01.009.

\section{Legislación}

Argentina. Ley 25 152, de 25 de agosto de 1999, Administración de los Recursos Públicos. Disponible en: https://goo.gl/Vm2Jni [consulta: 24-1-2015].

Argentina. Ley 25 917, de 25 de agosto de 2004, Régimen Federal de Responsabilidad Fiscal. Disponible en: https://goo.gl/zNecNk [consulta: 20-2-2015].

Argentina. Ley 26 739, de 22 de marzo de 2012, Banco Central de la República Argentina. Modifícase la Carta Orgánica. Disponible en: https://goo.gl/rQYE46 [consulta: 21-2-2015].

Argentina. Ley 26 784, de 1 de noviembre de 2012, Presupuesto General de la Administración Nacional para el Ejercicio 2013, capítulo VII: «De las operaciones de crédito público». Disponible en: https://goo.gl/VVf3kb [consulta: 21-2-2015].

Argentina. Ley 26 984, de 10 de septiembre de 2014, Títulos Públicos. Pago Soberano. Restructuración de Deuda. Disponible en: http://goo.gl/B9KxkN [consulta: 20-12-2015]. 
Argentina. Decreto 1359/2004, de 5 de octubre, Estructura Organizativa del ex Ministerio de Economía y Producción", anexo al artículo 2. Disponible en: https:// goo.gl/HjEPYQ [consulta: 19-3-2014].

Argentina. Decreto 1361/1994, de 5 de agosto, Administración Financiera y de los Sistemas de Control del Sector Público Nacional. Reglamento Parcial 3 de la Ley 24 156. Disponible en: https://goo.gl/dxNuXh [consulta: 25-1-2015].

Argentina. Decreto 2083/2009, de 15 de diciembre, Objetivos de la Secretaría de Finanzas del Ministerio de Economía y Finanzas Públicas.

\section{Comunicaciones gubernamentales}

AFIP. 2011. «Moneda Extranjera. Programa de Consulta de Operaciones Cambiarias. Creación». Resolución General 3210. Buenos Aires, 28 de octubre de 2011. MECON. 2015. «Desendeudar» [micrositio del Ministerio de Economía y Finanzas Públicas de la República Argentina. Disponible en: http://goo.gl/2YbD1X [consulta: 2-11-2015].

\section{Documentos Institucionales de la $A G N$}

AGN. Informes Anuales 1996 a 2013. Buenos Aires: Auditoría General de la Nación AGN. 2005. Análisis del Balance de Pagos. Indicadores de Vulnerabilidad Externa y Fiscal. Gerencia de Deuda Pública. Buenos Aires: Auditoría General de la Nación.

Presentado para evaluación: 31de julio de 2016.

Aceptado para publicación: 21 de junio de 2017.

\section{DANTE AVARO}

dante.avaro@7tres.biz

Investigador en el Consejo Nacional de Investigaciones Científicas y Técnicas de la República Argentina. Sus principales intereses incluyen la calidad de la democracia, sorteo y desacuerdos fácticos. Entre sus últimas publicaciones destaca: "Trazabilidad ciudadana y democracia: una aproximación desde la experiencia argentina", Revista Mexicana de Ciencias Políticas y Sociales, 231 (en prensa). 